\title{
Pengaruh Persepsi Siswa atas Kreativitas Guru dan Minat Belajar terhadap Hasil Belajar IPA
}

\author{
Wisnu Mursabdo \\ Prodi S2 MIPA, Universitas Indraprasta PGRI, Jakarta, Indonesia \\ E-mail: wisnu.mursabdo@gmail.com
}

Riwayat artikel: submit: 12 September 2021; revisi: 25 September 2021, diterima: 30 September 2021

\begin{abstract}
ABSTRAK
Penelitian ini bertujuan untuk mengukur besarnya pengaruh langsung dan tak langsung persepsi siswa atas kreativitas guru dan minat belajar terhadap hasil belajar IPA di SMP Kristen Kanaan Jakarta. Penelitian ini memiliki hipotesis : (1) terdapat pengaruh langsung signifikan persepsi siswa atas kreativitas guru terhadap minat belajar, (2) terdapat pengaruh langsung signifikan persepsi siswa atas kreativitas guru terhadap hasil belajar IPA; (3) terdapat pengaruh langsung signifikan minat belajar terhadap hasil belajar IPA. Metode penelitian yang digunakan adalah metode survei dengan analisis jalur (path analysis). Populasi adalah siswa SMP Kristen Kanaan Jakarta TA 2020/2021 yang berjumlah 140 siswa. Jumlah sampel adalah 50 siswa yang dipilih melalui teknik simple random sampling. Pengumpulan data dilakukan dengan kuisioner daring dan hasil belajar IPA yang diambil dari nilai semester 2. Hasil penelitian menunjukkan persepsi siswa atas kreativitas guru dan minat belajar memberi pengaruh besar terhadap hasil belajar IPA. Persepsi siswa atas kreativitas guru memberi pengaruh 55,5\% terhadap hasil belajar IPA, sedangkan minat belajar memberi pengaruh 30,3\% terhadap hasil belajar IPA. Besarnya pengaruh tak langsung persepsi siswa atas kreativitas guru terhadap hasil belajar IPA adalah sebesar 25,1\%. Pengaruh total persepsi siswa terhadap kreativitas guru dan minat belajar terhadap hasil belajar IPA adalah sebesar 76,9\%. Sedangkan hasil pengujian hipotesis menunjukkan : (1) terdapat pengaruh langsung persepsi siswa atas kreativitas guru terhadap minat belajar siswa; (2) terdapat pengaruh langsung persepsi siswa atas kreativitas guru terhadap hasil belajar IPA; (3) terdapat pengaruh langsung minat belajar terhadap hasil belajar IPA. Hasil penelitian ini menunjukkan bahwa hasil belajar IPA bisa ditingkatkan dari persepsi siswa atas kreativitas guru dan minat belajar.
\end{abstract}

Kata kunci: persepsi siswa atas kreativitas guru, minat belajar, hasil belajar IPA

\section{ABSTRACT}

This study aims to measure the direct and indirect influence of students' perceptions of teacher creativity and interest in learning on science learning outcomes at SMP Kristen Kanaan Jakarta. This study has hypotheses: (1) there is a significant direct influence on students' perceptions of teacher creativity on learning interest, (2) there is a significant direct influence of students' perceptions of teacher creativity on science learning outcomes; (3) there is a significant direct influence of interest in learning on science learning outcomes. The research method used is a survey method with path analysis. The population is SMP Kristen Kanaan Jakarta 2020/2021 students, totaling 140 students. The number of samples was 56 students who were selected through simple random sampling technique. Data was collected using online questionnaires and science learning outcomes were taken from semester 2 grades. The results showed students' perceptions of teacher creativity and interest in learning had a major influence on science learning outcomes. Students' perceptions of teacher creativity have an influence of $55.5 \%$ on science learning outcomes, while learning interest has an influence of $30.3 \%$ on science learning outcomes. The magnitude of the indirect effect of student perceptions of teacher creativity on science learning outcomes is $25.1 \%$. The total effect of students' perceptions on teacher creativity and interest in learning on science learning outcomes is $76.9 \%$. While the results of hypothesis testing show: (1) there is a direct influence of students' perceptions of teacher creativity on students' interest in learning; (2) there is a direct influence on students' perceptions of teacher creativity on science learning outcomes; (3) there is a direct influence of interest in learning on 
Mursabdo, W.(2021). Pengaruh Persepsi Siswa atas Kreativitas Guru dan Minat Belajar terhadap Hasil Belajar IPA. Edudikara: Jurnal Pendidikan dan Pembelajaran, 6(3), 216-225.

science learning outcomes. The results of this study indicate that science learning outcomes can be improved from students' perceptions of teacher creativity and interest in learning.

Keywords. students' perceptions of teacher creativity, interest in learning, science learning outcomes

Copyright $(0) 2021$ The Author(s)

This is an open access article under the CC BY-SA license.

\section{PENDAHULUAN}

Di jenjang pendidikan SMP, mata Pelajaran IPA menjadi momok pelajaran kedua setelah matematika. Siswa merasa susah mempelajari IPA karena terdapat unsur hafalan, rumus, dan perhitungan. Pada sub bab pelajaran Biologi, siswa harus menghafal materi yang berhubungan dengan makhluk hidup. Sedangkan pada sub bab pelajaran Fisika, siswa dituntut pemahaman perhitungan karena harus menyelesaikan soal dengan dasar matematika. Banyaknya rumus dan hitungan yang njelimet membuat siswa kurang berminat belajar IPA.

Padahal, pelajaran IPA adalah pelajaran tentang kehidupan, membahas fenomena alam di sekitar kita (Suendarti, 2019). Seharusnya IPA menjadi daya tarik siswa untuk belajar, apalagi pelajaran IPA juga kaya praktikum, hampir setiap pokok bahasan ada praktikum dan hampoir semua praktikum membahas fenomena alam.

Tetapi apa daya, stigma yang sudah tertanam, IPA adalah pelajaran susah dan membuat nilai jeblok. Kondisi diperparah dengan anggapan guru IPA adalah guru yang "galak", guru yang pelit nilai dan segudang anggapan-anggapan "sangar" lainnya.

Kondisi seperti ini tidak boleh dibiarkan dan menjadi tantangan guru IPA untuk terus memacu semangat belajar siswa. IPA atau Sains, selalu memegang peran dalam perkembangan peradaban manusia (Mursabdo, 2021). Tanpa IPA, maka kejauan teknologi tidak akan bisa seperti sekarang. Di saat bonus demografi nanti (kira-kita tahun 2030), IPA memegang peranan penting dalam perkembangan STEAM (Science Technology Engineering Art and Math).

Dari berbagai literatur, motivasi belajar siswa dipengaruhi oleh dua faktor, internal dan eksternal (Asroi \& Hidayat, 2013). Faktor internal adalah dorongan dari dalam sedangkan eksternal adalah faktor diluar siswa misalnya guru. Dalam penelitian ini akan mempelajari pengaruh dalam dan luar dalam kesuksesan belajar IPA di SMP Kristen Kanaan Jakarta.

Dari sisi guru sebagai pendorong eksternal, selain kemampuan pedagogik dan profesional, guru juga dituntut kreatif dalam penyampaian materi. Tidak ada yang salah dalam metode mengajar guru, baik yang masih konservatif ataupun yang sudah mengikuti perkembangan jaman seperti blended learning. Semua pembelajaran muaranya sama, menyampaikan materi kepada siswa. Hanya yang menjadi pertanyaan adalah, seberapa besar materi yang disampaikan guru bisa diserap secara baik oleh siswa. Guru perlu melakukan rekayasa atau kreativitas dalam pengajaran (Mursabdo, 2021). Sedikit modifikasi dalam mengajar, bisa memebrikan sentuhan lain dan kejutan bagi siswa sehingga siswa tertarik dan bisa menyerap pelajaran. Sebagai contoh sederhana, untuk menunjukkan kepada siswa tentang lapisan Bumi, guru dapat mengajak siswa bersama-sama mengamati telur rebus yang dibelah dua. Secara kasat mata terlihat 3 bagian telur, kulit/cangkang, selimut dan inti, sama halnya dengan Bumi yang memiliki 3 bagian, kulit, selimut dan inti Bumi.

Apalagi di masa pandemi yang notabene pembelajaran dilakukan secara daring. Kreativitas guru sangat menentukan penyerapan pembelajaran oleh siswa. Guru harus banyak memberikan sentuhan metode belajar baik yang pembelajaran langsung (sinkronos), maupun pembelajaran tak langsung melalui video pembelajaran. Guru juga harus bisa menguasai berbagai platform pembelajaran untuk bahan ajar kepada siswa (Mursabdo, 2021).

Sehebat-hebatnya dan sekreatif-kreatifnya seorang guru, bila tidak diimbangi dengan minat belajar siswa tentu hasilnya sia-sia belaka. Minat belajar adalah keinginan siswa dalam 
Mursabdo, W.(2021). Pengaruh Persepsi Siswa atas Kreativitas Guru dan Minat Belajar terhadap Hasil Belajar IPA. Edudikara: Jurnal Pendidikan dan Pembelajaran, 6(3), 216-225.

mempelajari pelajaran tertentu dengan disadari rasa senang dan tanpa paksaan (Asroi \& Hidayat, 2016). Minat belajar akan mendorong siswa untuk menyukai pelajaran, menggerakkan rutinitas belajar, menambah ketaatan pada guru, dan akhirnya menimbulkan keinginan untuk berprestasi.

Dalam penelitian ini, metode analisis yang digunakan adalah analisis jalur, dimana metode analisis ini mampu menghitung besarnya pengaruh antar variabel baik pengaruh langsung maupun tidak langsung. Penelitian ini paling tidak bisa memebrikan masukan kepada para guru IPA dan guru-guru di SMP Kristen Kanaan Jakarta untuk meningkatkan hasil belajar IPA melalui kreativitas dan minat belajar siswa.

\section{METODE}

Penelitian ini adalah penelitian kuantitatif yang bersifat asosiatif kausalitas dengan menggunakan metode survei pada pengumpulan datanya. Pengambilan sampel dilakukan secara simple random sampling. Jumlah sampel yang digunakan adalah 56 dari 140 jumlah populasi siswa SMP Kristen Kanaan Jakarta. Penyebaran kuesioner dilakukan secara daring dengan bantuan google form.

Ada tiga variabel yang diteliti dalam penelitian ini yaitu : persepsi siswa atas kreativitas guru $\left(X_{1}\right)$, minat belajar $\left(X_{2}\right)$ dan hasil belajar IPA $\left(X_{3}\right)$. Variabel $X_{1}$ dan $X_{2}$ dikumpulkan melalui survei daring, sedangkan variabel $X_{3}$ dikumpulkan dari nilai rapor semester 2 . Nilai variabel $X_{1}$ dan $\mathrm{X}_{2}$ didapatkan dari skoring instrumen penelitian yang didapatkan dari hasil survei.

Metode Analisis yang digunakan adalah adalah analisis jalur. Pengolahan data dilakukan menggunakan software SPSS. Besarnya pengaruh antar variabel ditentukan oleh nilai koefisien jalur (Setyaningsih, 2020). Besarnya pengaruh langsung variabel $X_{1}$ terhadap $X_{2}$ ditentukan oleh besarnya koefisien jalur $\rho_{21}$, besarnya pengaruh langsung $X_{1}$ terhadap $X_{3}$ ditentukan oleh besarnya koefisien jalur $\rho_{31}$, besarnya pengaruh langsung $X_{2}$ terhadap $X_{3}$ ditentukan oleh besarnya koefisien jalur $\rho_{32}$. Sedangkan besarnya pengaruh tidak langsung variabel $X_{1}$ terhadap $X_{3}$ ditentukan oleh hasil perkalian $\rho_{21}$ dengan $\rho_{32}$. Besarnya pengaruh total variabel $X_{1}$ terhadap $X_{3}$ adalah penjumlahan pengaruh langsung $X 1$ terhadap $X 3\left(\rho_{31}\right)$ dan pengaruh tak langsung $X_{1}$ terhadap $\mathrm{X}_{3}$.

Desain penelitian yang digunakan untuk mengetahui ada tidaknya pengaruh langsung dan tidak langsung antara ketiga variabel tersebut digambarkan dalam konstelasi masalah berikut :

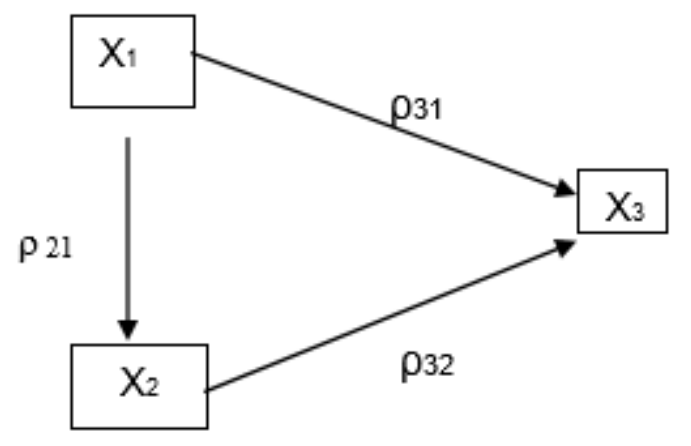

Gambar 1. Konstelasi Masalah

\section{Keterangan:}

$\mathrm{X} 1$ : Persepsi siswa atas kreativitas guru

$\mathrm{X}_{2}$ : Minat Belajar

$\mathrm{X}_{3}$ : Hasil belajar IPA

$\rho_{21}$ : koefisien jalur $X_{1}$ terhadap $X_{2}$ (pengaruh langsung $X_{1}$ terhadap $X_{2}$ ) 
Mursabdo, W.(2021). Pengaruh Persepsi Siswa atas Kreativitas Guru dan Minat Belajar terhadap Hasil Belajar IPA. Edudikara: Jurnal Pendidikan dan Pembelajaran, 6(3), 216-225.

$\rho_{31}$ : koefisien jalur $X_{1}$ terhadap $X_{3}$ (pengaruh langsung $X_{1}$ terhadap $X_{3}$ )

$\rho_{32}$ : koefisien jalur $X_{2}$ terhadap $X_{3}$ (pengaruh langsung $X_{2}$ terhadap $X_{3}$ )

\section{HASIL DAN PEMBAHASAN}

\section{Hasil Penelitian}

Hasil penelitian disajikan dalam analisis deskriptif, uji prasyarat, uji hipotesis dan analisis jalur.

\section{Analisis Deskriptif}

Dari hasil analisis deskriptif terhadap 50 siswa SMP Kristen Kanaan Jakarta, hasil belajar IPA tergolong cukup baik, dengan nilai rata-rata 79,58, dimana rentang nilai berada pada kisaran 75 sampai 95. Persepsi siswa atas kreativitas guru memiliki rata-rata 73,94 dengan rentang nilai antara 61 sampai dengan 86. Sedangkan minat belajar memiliki rata-rata 77,46 dengan rentang nilai dari 65 sampai dengan 87 . Hasil analisis deskriptif ini tersaji pada tabel 1.

Tabel 1. Statistik Deskriptif

\begin{tabular}{lllll}
\hline Variabel & N & Minimum & Maximum & Mean \\
\hline Persepsi Siswa Atas Kreativitas Guru & 50 & 61 & 86 & 73,94 \\
Minat Belajar & 50 & 65 & 87 & 77,46 \\
Hasil Belajar IPA & 50 & 75 & 95 & 79,58 \\
\hline
\end{tabular}

Sumber: Data primer yang diolah

\section{Uji Prasyarat}

Ada 3 uji prasayarat yang dilakukan sebelum melakukan uji hipotesis dan analisis jalur yaitu: uji normalitas residual, uji linearitas, dan uji multikolinearitas (Abdulwahab, 2013). Uji normalitas residual adalah uji untuk melihat normalitas residual, dimana residual harus menyebar normal. Uji linearitas adalah uji melihat hubungan linier antar variabel. Sedangka uji Multikolinearitas adalah uji untuk melihat tidak terdapat korelasi antar variabel bebas atau tidak ada korelasi $X_{1}$ dan $X_{2}$ dalam penelitian ini..

Uji normalitas residual dilakukan dengan uji Kolmogorov-Smirnov. Ada 3 uji yang dilakukan yaitu uji normalitas residual $X_{3}$ atas $X_{1}$, uji normalitas residual $X_{3}$ atas $X_{2}$, dan uji normalitas residual $X_{2}$ atas $X_{1}$. Hasil pengujian menunjukkan uji prasyarat normalitas terpenuhi seperti ditampilkan pada Tabel 2. Uji normalitas terpenuhi jika nilai perolehan Asymp. Sig.(2-tailed) lebih dari 0,05 (Perdana, 2016).

Tabel 2. Hasil Uji Normalitas Kolmogorov-Smirnov

\begin{tabular}{lll}
\hline Uji Normalitas Residual & Test Statistic & Asymp. Sig.(2-tailed) \\
\hline$X_{3}$ atas $X_{1}$ & 0,096 & 0,200 \\
$X_{3}$ atas $X_{2}$ & 0,120 & 0,068 \\
$X_{2}$ atas $X_{1}$ & 0,076 & 0,200 \\
\hline
\end{tabular}

Sumber: Data primer yang diolah

Uji linieritas dilakukan dengan uji compare mean. Terdapat hubungan linier antar variabel jika nilai perolehan Sig. lebih dari 0,05. Dalam penelitian ini, secara umum terdapat hubungan linier antar variabelnya.

Tabel 3. Hasil Uji Linieritas 
Mursabdo, W.(2021). Pengaruh Persepsi Siswa atas Kreativitas Guru dan Minat Belajar terhadap Hasil Belajar IPA. Edudikara: Jurnal Pendidikan dan Pembelajaran, 6(3), 216-225.

\begin{tabular}{lll}
\hline Uji Linieritas & F hitung & Sig. \\
\hline$X_{3}$ atas $X_{1}$ & 1,908 & 0,058 \\
$X_{3}$ atas $X_{2}$ & 2,538 & 0,012 \\
$X_{2}$ atas $X_{1}$ & 1,638 & 0,114 \\
\hline
\end{tabular}

Sumber: Data primer yang diolah

Meskipun hasil uji linearitas $X_{3}$ atas $X_{2}$ tidak linier pada taraf nyata $0,05(5 \%)$, namun variabel $X_{3}$ dan $X_{2}$ linier pada taraf nyata 0,01 (1\%). Jadi dapat disimpulkan jika $X_{3}$ dan $X_{2}$ linier.

Uji multikolineraitas dilakukan dengan melihat nilai tollerance dan VIF (varians inflation factor). Tidak adanya korelasi antar variabel dengan ditunjukkan nilai tollerance lebih besar dari 0,1 dan nilai VIF kurang dari 10 (Janie, 2012).

Tabel 4. Hasil Uji Multikolinearitas

\begin{tabular}{lll}
\hline Model & VIF & Tolerance \\
\hline Persepsi Siswa atas Kreativitas Guru & 3,189 & 0,314 \\
Minat Belajar & 3,189 & 0,314 \\
\hline
\end{tabular}

Sumber: Data primer yang diolah

\section{Uji Hipotesis}

Ada 3 hipotesis yang akan diuji dalam peneltian ini yaitu : 1) Terdapat pengaruh langsung yang signifikan persepsi siswa atas kreativitas guru terhadap minat belajar. 2) Terdapat pengaruh langsung yang signifikan persepsi siswa atas kreativitas guru terhadap hasil belajar IPA. 3) Terdapat pengaruh langsung yang signifikan minat belajar terhadap hasil belajar IPA

\section{Uji Hipotesis 1}

Untuk menguji adanya pengaruh langsung persepsi siswa atas kreativitas guru terhadap minat belajar adalah menggunakan uji t. Hasil uji menunjukkan pengaruh langsung signifikan jika perolehan nilai Sig. kurang dari 0,05 (Mustakin, 2019).

Dari hasil pengujian dari Tabel 5, maka dapat disimpulkan terdapat pengaruh langsung yang signifikan persepsi siswa atas kreativitas guru terhadap minat belajar.

Tabel 5. Hasil Uji Hipotesis 1

\begin{tabular}{llll}
\hline & t hitung & Sig. \\
\hline $\begin{array}{l}\text { Pengaruh Langsung Persepsi Siswa Atas } \\
\text { Kreatifitas Guru Terhadap Minat Belajar }\end{array}$ & & 0,000 \\
\hline Sumber: Data primer yang diolah
\end{tabular}

\section{Uji Hipotesis 2}

Untuk menguji adanya pengaruh langsung persepsi siswa atas kreativitas guru terhadap hasil belajar IPA adalah menggunakan uji t. Hasil uji menunjukkan pengaruh langsung signifikan jika perolehan nilai Sig. kurang dari 0,05.

Dari hasil pengujian dari Tabel 6 , maka dapat disimpulkan terdapat pengaruh langsung yang signifikan persepsi siswa atas kreativitas guru terhadap hasil belajar IPA. 
Mursabdo, W.(2021). Pengaruh Persepsi Siswa atas Kreativitas Guru dan Minat Belajar terhadap Hasil Belajar IPA. Edudikara: Jurnal Pendidikan dan Pembelajaran, 6(3), 216-225.

Tabel 6. Hasil Uji Hipotesis 2

\begin{tabular}{lll}
\hline & t hitung & Sig. \\
\hline $\begin{array}{l}\text { Pengaruh Langsung Persepsi Siswa Atas Hasil } \\
\text { Belajar IPA }\end{array}$ & 3,767 & 0,000 \\
\hline Sumber: Data primer yang diolah & &
\end{tabular}

\section{Uji Hipotesis 3}

Untuk menguji adanya pengaruh minat belajar terhadap hasil belajar IPA adalah menggunakan uji t. Hasil uji menunjukkan pengaruh langsung signifikan jika perolehan nilai Sig. kurang dari 0,05.

Dari hasil pengujian dari Tabel 7, maka dapat disimpulkan terdapat pengaruh langsung yang signifikan minat belajar terhadap hasil belajar IPA.

Tabel 7. Hasil Uji Hipotesis 3

\begin{tabular}{llll}
\hline & thitung & Sig. \\
\hline $\begin{array}{l}\text { Pengaruh Langsung Persepsi Siswa Atas } \\
\text { Kreatifitas Guru Terhadap Minat Belajar }\end{array}$ & & 0,056 \\
\hline Sumber: Data primer yang diolah & & \\
\hline
\end{tabular}

\section{Analisis Jalur}

Berdasarkan output SPSS tentang analisis jalur, maka dapat digambarkan besarnya koefisien jalur dalam diagram berikut :

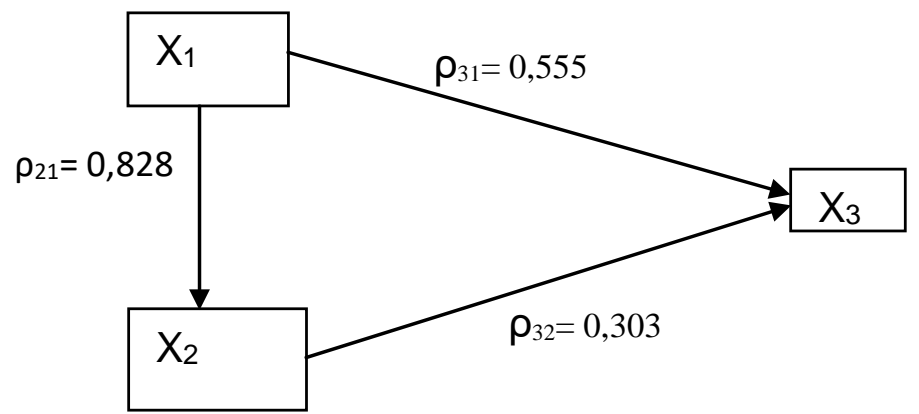

Gambar 2. Diagram Koefisien Jalur

Berdasarkan analisis dan visual Gambar 2, dapat dilihat besarnya pengaruh langsung antar variabel. Besarnya pengaruh langsung persepsi siswa atas kreativitas guru terhadap minat belajar adalah sebesar $82,8 \%$. Besarnya pengaruh persepsi siswa atas kreativitas guru terhadap hasil belajar IPA adalah $55,5 \%$, sedangkan besarnya pengaruh langsung minat belajar terhadap hasil belajar IPA adalah 30,3\%.

\section{Pembahasan}

Pengaruh Langsung Persepsi Siswa Atas Kreativitas Guru Terhadap Minat Belajar

Persepsi siswa atas kreativitas guru memberi pengaruh langsung sebesar $82,8 \%$ terhadap minat belajar. Ini menunjukkan bahwa peran guru masih sangat besar dalam proses pembelajaran IPA di SMP Kristen Kanaan Jakarta. Kondisi ini mensyaratkan guru masih sebagai "play maker" dalam dunia pengajaran. Hal ini masih bisa dimaklumi mengingat kemampuan 
kognitif siswa tingkat SMP masih terbatas soal IPA dan adanya peralihan pola pikir dari SD ke SMP. Guru IPA di jenjang SMP harus bisa merangsang minat belajar siswa melalui berbagai kreativitas dalam pembelajaran, baik dalam aspek pengetahuan maupun aspek ketrampilan.

Mata Pelajaran IPA bukanlah mata pelajaran garing, IPA adalah dinamis. IPA membahas fenomena alam baik yang biotik maupun abiotik. IPA memang banyak rumus dan hitungan, tetapi IPA memiliki daya tarik pada aspek ketrampilan. Hampir setiap bab pelajaran IPA selalu ada praktikum. Praktikum adalah salah satu cara menanamkan konsep kepada siswa melalui pengalaman langsung. Praktikum bisa dilakukan di dalam ruang lab, bisa juga dilakukan di luar ruangan. Bahkan di jaman digital sekarang, praktikum juga dilakukan melalui ruang maya.

Pengalaman langsung yang diterima siswa baik dari aspek kognifik dan aspek psikomotorik ini bisa memebri daya dorong minat belajar siswa kepada IPA. Guru juga perlu sedikit memberi sentuhan-sentuhan kreativitas dalam pembelajaran IPA, misalnya guru memvariasi ceramah dengan video pembelajaran untuk menarik minat belajar siswa.

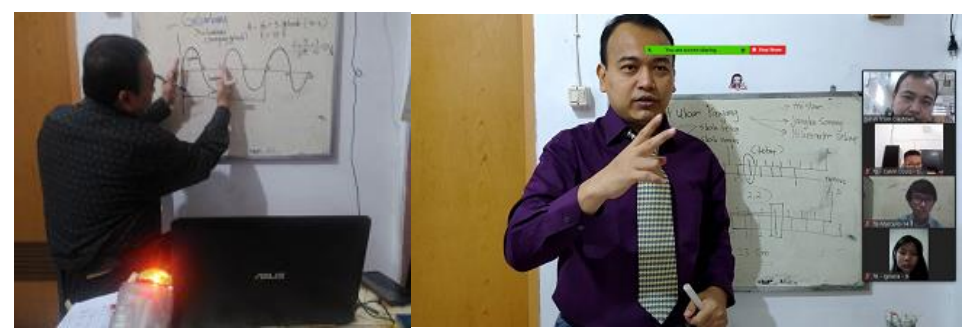

Gambar 3. Kreatifitas guru dalam pembelajaran dengan memvariasi metode ceramah dengan video pembelajaran

\section{Pengaruh Langsung Persepsi Siswa Atas Kreativitas Guru Terhadap Hasil Belajar IPA}

Persepsi siswa atas kreativitas guru memberi pengaruh langsung kepada hasil belajar IPA sebesar 55,5\%. Ini menunjukkan bahwa separuh lebih hasil belajar IPA di SMP Kristen Kanaan Jakarta masih ditentukan oleh faktor guru. Meski dalam tanda kutip masih menjadi tokoh sentral, guru harus terus belajar untuk meng-upgrade pengetahuan dan ketrampilan.

Tuntutan guru di abad 21 adalah profesionalisme (Hidayat, 2015). Guru abad 21 dituntut untuk mampu beradaptasi dengan teknologi. Sesuai tuntutan jaman, guru IPA harus bisa berkontribusi kepada perkembangan STEAM (science, technology, enginering, arth, math). Kolaborasi pengetahuan IPA dengan STEAM diharapkan mampu menarik minat belajar siswa.

Melalui pelatihan atau seminar, guru bisa meningkatkan kemampuannya untuk kemudian diimplementasikan dalam pembelajaran di kelas.

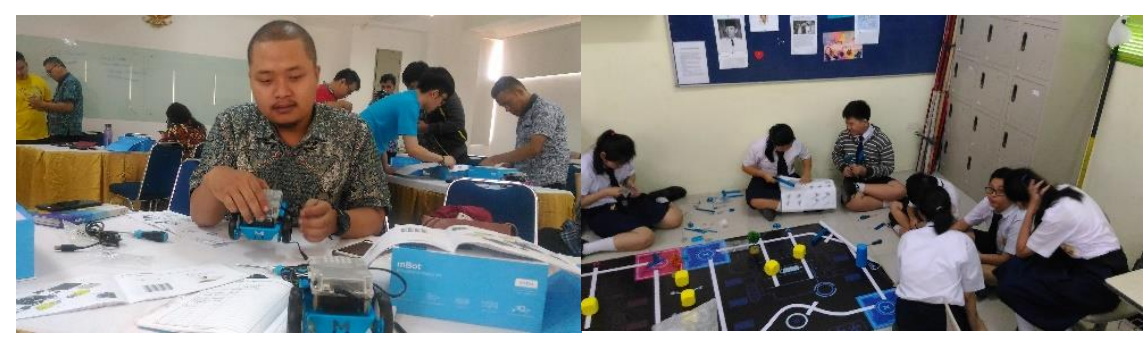

Gambar 4. Pelatihan dan seminar untuk meningkatkan kreativitas guru dalam pembelajaran

\section{Pengaruh Langsung Minat Belajar Terhadap Hasil Belajar IPA}

Pengaruh langsung minat belajar terhadap hasil belajar IPA adalah sebesar $30,3 \%$. Secara angka mungkin terlihat kecil, namun secara statistik, minat belajar memberi pengaruh langsung yang signifikan terhadap hasil belajar IPA di SMP Kristen Kanaan Jakarta. 
Mursabdo, W.(2021). Pengaruh Persepsi Siswa atas Kreativitas Guru dan Minat Belajar terhadap Hasil Belajar IPA. Edudikara: Jurnal Pendidikan dan Pembelajaran, 6(3), 216-225.

Langsung atau tidak langsung, minat belajar dipengaruhi oleh guru yang masih menjadi sentral dalam kelas. Faktor guru menjadi pendorong siswa untuk belajar. Suasana belajar yang nyaman membuat siswa termotivasi untuk belajar. Kreativitas pembelajaran yang diberikan oleh guru baik dalam kelas dapat memicu anak untuk belajar.

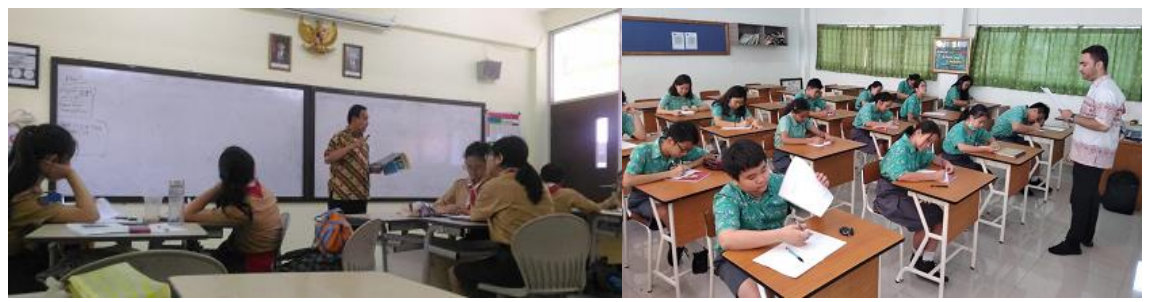

Gambar 5. Penciptaan suasana kelas yang nyaman untuk menarik minat belajar siswa

\section{Pengaruh Tak Langsung Persepsi Siswa Atas Kreativitas Guru Terhadap Hasil Belajar IPA}

Selain pengaruh langsung, dapat pula dihitung besarnya pengaruh tak langsung persepsi siswa atas kreativitas guru terhadap hasil belajar IPA, yaitu dengan mengalikan $82,8 \%$ dengan $30,3 \%$. Hasil perhitungan pengaruh tak langsung pengaruh persepsi siswa atas kreativitas guru terhadap hasil belajar IPA adalah $25,1 \%$. Sedangkan besarnya total pengaruh persepsi siswa atas kreativitas guru terhadap hasil belajar IPA adalah $80,6 \%$ dengan menjumlahkan pengaruh langsung dan tak langsung yaitu $55,5 \%$ ditambah $25,1 \%$.

\section{SIMPULAN DAN SARAN}

Pengaruh persepsi siswa atas kreativitas guru dan minat belajar memberi pengaruh pengaruh signifikan terhadap hasil belajar IPA. Pengaruh persepsi siswa terhadap kreativitas guru terhadap hasil belajar IPA adalah sebesar 55,5\%. Sedangkan minat belajar memberi pengaruh 30,3\% terhadap hasil belajar IPA. Dibandingkan dengan minat belajar, persepsi siswa atas kreativitas guru adalah variabel yang paling berpengaruh terhadap hasil belajar IPA.

Penelitian ini masih jauh dari kata sempurna mengingat kontribusi persepsi siswa atas kreativitas guru dan minat belajar terhadap hasil belajar IPA adalah sebesar 68\%, sedangkan sisanya $32 \%$ disebabkan oleh faktor lain yang tidak diteliti.

Untuk meningkatkan hasil belajar IPA dapat ditingkatkan dengan meningkatkan persepsi siswa atas kreativitas guru. Guru di era milenial dituntut untuk bisa menyesuaiakn kebutuhan jaman sehingga materi ajar yang diberikan dapat diserap oleh siswa.

Perlu dilakukan penelitian lanjutan baik yang bersifat kualitatif ataupun kuantitatif untuk memperbaiki ketidaksempurnaan pada penelitian ini.

\section{REFERENSI}

Abdulwahab, Wisnijati Basuki. (2013). Statistika Parametrik dan Nonparametrik untuk Penelitian. Jakarta : Pustaka Mandiri.

Asroi \& Hidayat, Syarif. (2016). Memahami Variabel dan Instrumen Penelitian. Jakarta: Pustaka Mandiri. Hidayat, Syarif \& Asroi. (2013). Manajemen Pendidikan. Jakarta: Pustaka Mandiri.

Hidayat, Syarif. (2015). Teori dan Prinsip Pendidikan. Jakarta : Pustaka Mandiri.

Janie, Dyah Nirmala Arum. (2012). Statistik Deskriptif \& Regresi Linier Berganda dengan SPSS. Semarang : Semarang University Press.

Mursabdo, Wisnu. (2021). Pengaruh Pandemi Covid-19 terhadap Proses Pembelajaran di SMP Kristen Kanaan Jakarta. https://widyasari-press.com/pengaruh-pandemi-covid-19-terhadap-prosespembelajaran/

Mursabdo, Wisnu \& Mursabdo, Michael Christian. 2021. Efektivitas Pembelajaran Daring Terhadap Daya Serap Siswa Kelas 9 SMP Kristen Kanaan Jakarta. Sumbawa Barat: Jurnal Lentera. 
Mursabdo, W.(2021). Pengaruh Persepsi Siswa atas Kreativitas Guru dan Minat Belajar terhadap Hasil Belajar IPA. Edudikara: Jurnal Pendidikan dan Pembelajaran, 6(3), 216-225.

Mutakin, Tatan Zaenal \& Suendarti, Mamik. (2019). Bahan Praktek Pengolahan Data Design and Analysis of Experiments. Jakarta : Pustaka Mandiri.

Perdana, Echo. (2016). Olah Data Skripsi dengan SPSS 22. Pangkalpinang : Lab Kom Manajemen FE UBB. Setyaningsih, Sri. (2020). Manajemen Pendidikan Melalui Analisis Jalur (Path Analysis) dan Metode SITOREM. Bandung : Penerbit Alfabeta

Suendarti, Mamik. (2019). Konsep-konsep MIPA. Jakarta: Pustaka Mandiri. 